\title{
When Your Audience Is Your Channel: Facebook for Behavior Change
}

\author{
Drew Bernard and Sarah Francis
}

As we write this chapter in the summer of 2020, a growing list of advertisers are participating in a boycott of Facebook. Mark Zuckerberg, the founder of Facebook, appeared before the US Congress again to testify on how Facebook uses its data and interacts with other social media applications. Questions fly through the news about how powerful Facebook is and how its applications can be used for harm and disseminating misinformation. But what if the same characteristics that make Facebook so effective for spreading false information were instead harnessed for social good? For years, nonprofits have watched as the Internet and mobile technology have transformed society and communication. They recognize the promise that Facebook and other social media hold for serving audiences and changing behavior but have struggled to use the platform to drive measurable, real-world, impact. Many practitioners still point to meaningless

D. Bernard $(\bowtie)$

Upswell, Portland, OR, USA

e-mail: drew@teamupswell.com

S. Francis

Upswell, Seattle, WA, USA

e-mail: sarah@teamupswell.com

(C) The Author(s) 2021

L. B. Frank, P. Falzone (eds.), Entertainment-Education Behind the

Scenes, https://doi.org/10.1007/978-3-030-63614-2_19 
metrics such as the number of people reached or even fan counts to justify their investments. Yet platforms such as Facebook can be remarkably efficient and effective channels for delivering measurable behavior change outcomes. Founded by Drew Bernard and Sarah Francis in 2017, Upswell helps organizations tap the full power of platforms such as Facebook to create a healthier, more just, and joyful world. One of the ways we do this is by providing global health organizations with the strategies, training, tools, and insights they need to succeed.

\section{It's About the Community, Not the Company}

Like all social media applications, without its users, Facebook is just a platform, an empty blue dot on your phone. What makes Facebook useful for behavioral change communication is that Facebook is a community. It's a place where people come to engage with the people they care about and who care about them. According to their 2019 financial filings, Facebook had 2.5 billion monthly active users by the end of 2019 , the most of any social network. In July 2020, more than $98 \%$ of active users accessed Facebook through their mobile phones (Clement, 2020). Despite this impressive number, when planning to use Facebook, you must first do your research to determine whether people in your intended audience or the community you plan to reach are on the platform. Fortunately, Facebook provides tools that make this quick and easy.

Facebook is a channel where people come to find things they think are important or valuable and share them with each other. Trust in institutions is declining. In a recent study, just $41 \%$ of people say they trust mass media (Brenan, 2019), and only 19\% trust the national government (Pew Research Center, 2019). However, all around the world a whopping 83\% of people trust the information they get from friends and family (Nielsen, 2015 ). This means that it is more important than ever to get information to people in ways that lead them to share it with friends and family members. Entertainment-education programs have long recognized the importance of audiences discussing and sharing information about the programs with each other, using interpersonal discussions as a key outcome in program evaluation (Chatterjee, Bhanot, Frank, Murphy, \& Power, 2009; Sood, 2002). Talking positively about a campaign can also mediate the impacts the campaigns have on social norms and behavior (Frank et al., 2012). Thus, a channel that facilitates sharing among friends is an ideal venue for entertainment-education programming. 


\section{The Audience Is Your Channel}

Unlike traditional broadcast channels, on social media, content that people believe has value can earn far more exposure, as users share the messages with their community. This audience sharing not only amplifies the message and distributes it further but also makes it more powerful. However, on social media, the original content creator does not have complete control over the message. This is especially true when content is shared multiple times by multiple people. Indeed, Shi, Pooirsay, and Salmon (2018) identify multiple layers of sources of social media content including the originating organization, the technology platform, and the friend who shared the message. Because a friend becomes the source of a shared message, the organization's credibility may not matter as much for persuasion. Instead, people judge the content based on the fact that their friend found it valuable to share. When people comment on and counter misinformation on Facebook, their remarks can be effective in correcting audience perceptions (Bode \& Vraga, 2018).

Because Facebook and social media are amplified when people share, social and behavior change campaigns on these platforms need to reconsider their audience. Move from thinking of your intended audience to thinking of the people who care about, influence, and engage with that intended audience. In other words, if you want to talk to moms, you'll certainly want to reach other moms who they engage with. But at the same time, you'll want to think about who are the people who talk to moms, and arm them with the materials they can use to reach out to them. Give grandma, grandpa, brothers and sisters, aunts and uncles, and friends content that they will find valuable to share with the moms you ultimately hope to reach and influence. Essentially, you are adding one layer of abstraction, or thinking one step beyond the actual audience to their social network connections. This idea of multiple audiences is already an established practice in some more traditional entertainment-education programs using broadcast media. Frank, Jodrell, and Smethurst (2017) found that for pregnant women in Bangladesh, the primary influencers on decisions for prenatal care were their husbands and mothers-in-law. BBC Media Action used this information to craft their television drama, Ujan Ganger Naiya (Swimming Against the Tide), to target all three groups and encourage them to talk about the show and prenatal care. On Facebook, the key influencers are the people who care about and will share your content with your intended audience. 
We took advantage of this leveraging in our "Ring of Fire" advocacy campaign for Population Services International (PSI) in Myanmar. Our ultimate goal was to persuade politicians to support financing of universal health care by increasing their understanding of the issue and motivating them to act. Our formative research showed us that four key groups influenced these politicians: their wives, their friends, their staff, and the news media. Through Facebook, we were able to target the first three of these audiences that were adjacent to the decision makers. We created four different audience panels on Facebook: (1) the 2600 decision makers, (2) the 2800 wives of decision makers, (3) the 5800 staff of the decision makers, and (4) the 500,000 friends connected to the decision makers online. When we launched the campaign, we targeted the three audiences of wives, staff, and friends. Within three months, those audiences shared content from the campaign more than 5000 times and reached more than 275,000 people. By its conclusion, the campaign had 10,000 shares and reached 429,000 people. How did we do this? By focusing our energy on reaching the audiences who influence politicians: friends, voters, and key constituents. We used advertising to reach those audiences so they would engage with, comment on, and share our messages. The politicians ultimately saw our messages but did not receive them through advertisements from our campaign. Instead, they saw the messages coming from their friends, voters, and key constituents.

\section{The Power of Sharing}

There are three primary reasons that people share content on Facebook: (1) to define who they are, (2) to be of value to their friends, and (3) to make a positive difference in their community or the world. When making decisions about whether to share content, people consider how it will make them look. This self-defining consideration is not just about trying to make themselves look good. Instead, it's a litmus test of whether the content will help them demonstrate who they are and who they want to be. For example, in his study of why Facebook users changed their profile picture to the red equal sign supporting marriage equality, Penney (2015) found that many did so as a means to create a collective identity supporting lesbian, gay, bisexual, and transgender (LGBT) rights. Such sharing helps people to show who they are and try to inspire others on Facebook. The most important reason people share is because they believe the content will be valuable for their friends. This value can take many forms from 
being informational and life-saving to simply a funny story that will make friends smile. More broadly, people also share content that can make a change in the world beyond their immediate friend circle. In this way, Facebook users are determining whether the content can have an impact, whether sharing is going to make a difference given how much information is regularly shared, and whether the content simply needs more eyeballs. People share content that they believe benefits everybody, not just their friends.

Taken together, that means that our job as content creators is to create content that your target audience can use to serve the people they care about. We aim to create content that can serve the person who receives it by enabling them to do something for their friends. In our work for the Centers for Disease Control and Prevention (CDC), we developed a tool to help content creators assess their campaign before they share it on social media. The tool asks organizations to rate whether the content is relevant for their intended audience, has high emotional value, and conveys its message without requiring much time or thought. It further asks the extent to which people who see the content will want to share their own thoughts about it, believe their friends will get value from it, feel it shows their friends something positive about them, and help them make a difference in their community. Running through this kind of checklist can improve content. But it's just our best guess of how campaigns will do. What you think is going to work is probably wrong, so we can use Facebook and our audience to improve the content before we share it widely.

\section{Facebook as a Research ToOL}

The Facebook platform allows you to conduct research to inform your campaign before, during, and after you implement it. As a formative process of campaign development, nonprofits can use Facebook's Audience Insights tool to learn about their intended audiences. For example, to promote iron-folic acid supplements, Upswell and our partners chose an audience of women who were in the age group of 15-49 and lived in the Indian states of Madhya Pradesh and Uttar Pradesh. We were able to determine that 9.4 million women on Facebook met these inclusion criteria (Bernard, McCullough, Francis, Holton, \& Diamond-Smith, 2019). Once we identified our audience, we used Facebook to better understand what content would resonate with them. Facebook's Audience Insights 
tool provided more information on women's education, job, relationship status, interests, and hobbies.

Rather than trying to pick the winning content and then develop few high-cost pieces of content, we worked with our partner agency in India, Rabbithole, to develop 104 inexpensive posts with seven different styles of art but similar messages. To keep costs down, we used memes and animated gifs to learn what types of content engaged our audience. Our production team placed bets in advance on which of the messages we thought would succeed or fail. We were completely wrong; one of the memes we believed was sure to fail received the second-highest engagement. The 104 simple messages that we tested reached over a million Facebook users. Together, they garnered 570,382 likes, comments, and shares (Diamond-Smith, Holton, Francis, \& Bernard, 2020). More importantly, we were able to determine which of the simple posts resonated best. Through their engagement and reactions to the pilot messages, our audience taught us what they liked and believed was most valuable for their friends. Armed with these insights, we then developed more elaborate content: videos and stories to be used in our primary campaign. Don Green (2021) has called for formative research on entertainment-education narratives that includes testing multiple different versions that add or subtract specific narrative mechanisms to learn what works. As he detailed in his chapter, this type of intensive, multiple stimulus research can be costly and difficult. However, platforms like Facebook make it more feasible to rapidly conduct such tests. Our final campaign was based on audience-informed content.

Because our goal for these types of campaigns is measurable behavior change, reach (how many Facebook users were exposed to the campaign) is not a good early indicator of success. Instead, we focus on engagement. There is a hierarchy of engagement with likes and other Facebook reactions being the simplest and least meaningful way to interact with a post. Comments demonstrate a deeper level of engagement. By analyzing comments on our iron-folic acid campaign, we were able to learn that women had no readily accessible source for learning the answers to their questions about anemia, an insight that led us to quickly create a social media optimized website to answer their questions. Even more than commenting, the most meaningful early indicator of effective social content is sharing, whether by reposting the content or tagging a friend. This form of engagement increases the reach of the campaign and adds the source credibility of a friend recommending the content. Sharing messages indicates that the 
content is of value to friends and families. However, we must consider the context for sharing and viral spread. Sometimes people share information that they see as wrong. When a local politician in Nigeria posted on Facebook that meningitis was a curse from God for having premarital sex, the post went viral by being shared extensively. Rather than immediately shutting down the spread of that misinformation, it was important to look at why people were sharing and what they were saying as they did. The vast majority of shares included comments denouncing the misinformation and encouraging friends to get vaccinations. It's not sufficient to use Facebook likes or share counts to determine what content works. Instead, it's important to understand exactly what people are saying and why they choose to spread information or not.

Additionally, we can use Facebook as a tool to recruit participants for surveys that we launch outside of the Facebook platform (Bernard et al., 2019). As COVID-19 spread globally, we were connected with the producers of Shuga, an entertainment-education show airing in Nigeria and South Africa, who wanted to learn more about their audience and what the audience knew already about COVID-19. We were able to quickly use Facebook to reach viewers of the show. We used a Facebook advertisement to invite participants to complete a survey that we ran on Qualtrics. We intentionally did not say much about the purpose of the survey, so that we would not skew the results. Instead, we simply advertised the opportunity to be heard and to receive a small monetary incentive for completing the survey. We were surprised to learn that $89 \%$ of MTV Shuga viewers were already able to accurately identify action steps to prevent COVID-19 they learned from the show. We expect to do further research to compare viewers to non-viewers. The Facebook platform allowed us to recruit very quickly and inexpensively for a survey that could inform programming.

Facebook analytics and advertising tools allow us to learn and evolve in the midst of the campaign. As we learn which campaign messages resonated most strongly, we spend advertising dollars to boost those messages to our intended audience. The more engaging the message is, the more cost-effective it is as people distribute it beyond the advertising reach.

\section{Black Dog Case Study}

One of my favorite examples of this strategy in action is a piece of content created and shared by the World Health Organization (WHO) on World Health Day in 2016. In the months running up to that event, we 
consulted with the WHO on how they could better leverage Facebook in their communication initiatives. After working with them to identify the key factors that inspire their audiences to share content with friends and family members, they quickly put them to use to address the stigma around mental health, the topic of their 2016 World Health Day. The WHO team created content that people can use to support people who are suffering from depression and released it on Facebook. Based on a book by Matthew Johnstone (2007), the "Black Dog" video was a four-minute narrated video with captions. The video incorporated the static graphics from the original book, so production was not expensive. Using the metaphor of a black dog to represent depression, the video said, "Because of the shame and stigma of the black dog, I was constantly worried that I would be found out. So I invested vast amounts of energy into covering him up." It describes the author's story of feeling isolated and his journey toward recovery using professional help. WHO shared the video on their page on October 7, 2016, with a caption that read in part, "If you are in difficulty, never be afraid to ask for help. There is absolutely no shame in doing so."

WHO's "Black Dog" video demonstrates the startling impact that sharable health content can have. Within days more than 9000 people commented on the Black Dog video. Many of the comments on the WHO post were positive and grateful for the content. For example, one of the early commenters wrote, "Great to see this video, hopefully it will help destigmatize depression and allow people to feel comfortable in sharing their challenges with others. There is a solution to depression, people need not suffer in silence." However, some of the comments were less immediately positive. Another early commenter responded to the video that, "It sounds so easy. My black dog cannot easily be chased away as it comes with a red chronic pain ... It's nearly impossible to keep the black dog outside the room or my thoughts. When the consultants shake their head and pain attacks ... life becomes very difficult!" The WHO actively moderated comments on their post, and they responded, "Thanks for sharing your story with us. We understand it can be really difficult, but talking about depression is the very first step towards recovery." This active engagement with the audience yielded a positive response, "Absolutely! The discussion has got to start somewhere."

This video about the stigma of depression, specifically designed for people to share with those who might suffer, was shared more than 36,000 times in the first 34 hours and more than 74,000 times to date. People shared it directly with their friends who they worried might be 
experiencing depression with messages saying they were thinking of the friend and hoping the friend was doing well. In an exemplar comment in which one friend tagged another, she said, "our talks last Sunday ... this helps me make more sense of it," and her friend replied, "Thanks for sharing this ... it still helps to know." Shares like these were entirely organic with no money spent on advertising on the Facebook platform. In total, the content related to WHO's year-long mental health campaign including its flagship Black Dog post reached more than 18 million people.

Working with a Facebook brand lift study, we conducted a follow-up survey to learn why people shared the video. Brand lift studies provide deidentified and anonymous responses to simple questions. With a sample of 460 people, we asked whether people had shared for each of the three reasons that we have found typically motivate sharing. Of the people polled afterward, $60 \%$ said they shared it because they felt like it would help friends struggling with depression, and $72 \%$ said they felt everyone could benefit from watching it.

\section{Best Practices and Lessons Learned}

These lessons are about the use of Facebook specifically, but as social media evolves, they will continue to remain true for harnessing the influence of the audience. The power of social media comes from the power of the people who are using it to engage with each other.

Use the ability to rapidly test, learn, and evolve to conduct research. The fastest path to success goes directly through failure. By testing a high volume of low-cost, low-quality content, you can gain insights that augment other forms of market research. Fail fast and fail cheap to learn which messages will or won't resonate with the audience you hope to reach.

Manage your community. In using social media to distribute content, you are trying to arm people with material they can use to help you accomplish your mission. People are going to leave comments, ask questions, and engage with your content. Don't leave those comments unattended. Based on our years of experience with social causes on Facebook, we recommend that you (1) like all positive comments, (2) hide comments that are irrelevant or threatening to other members of your audience, and (3) answer all questions. When you can hide comments, the person who wrote the comment won't know they are hidden. If someone is attacking others, you can also block them. But generally, the best option is to write back and engage with people who comment. Your audience assumes a real 
person is behind your page, so you must interact and respond. To help you manage your time in responding to questions, you can develop a script of likely questions and possible answers in advance.

Your job is to create content that the person you're sending it to can use to care for people. When you see that content is taking off and being shared, you can put ad dollars behind that content to boost it. Doing so is an extremely cost-effective way of spreading your message to a wider audience. Higher impact content decreases the cost of reaching your audience by earning additional exposure.

Let your audience inform your content. Don't fall into the trap of believing that you know what is best. Think of your audience as your partner in how to create the most engaging content. Evaluate your campaign every day, and keep changing to boost what works with your audience and abandon what does not engage them.

\section{REFERENCES}

Bernard, D., McCullough, C., Francis, S., Holton, A., \& Diamond-Smith, N. (2019). Facebook powered measurement and evaluation for iron folic acid health intervention in India. Gates Open Research, 3, 1536. https://doi. org/10.12688/gatesopenres.13047.2

Bode, L., \& Vraga, E. K. (2018). See something, say something: Correction of global health misinformation on social media. Health Communication, 33(9), 1131-1140. https://doi.org/10.1080/10410236.2017.1331312

Brenan, M. (2019, September 26). Americans' trust in mass media edges down to $41 \%$. Retrieved from https://news.gallup.com/poll/267047/americans-trustmass-media-edges-down.aspx

Chatterjee, J. S., Bhanot, A., Frank, L. B., Murphy, S. T., \& Power, G. (2009). The importance of interpersonal discussion and self-efficacy in knowledge, attitude, and practice models. International Journal of Communication, $3,607-634$.

Clement, J. (2020, July 24). Device usage of Facebook users worldwide as of July 2020. Retrieved from https://www.statista.com/statistics/377808/ distribution-of-facebook-users-by-device/

Diamond-Smith, N., Holton, A. E., Francis, S., \& Bernard, D. (2020). Addressing anemia among women in India-An informed intervention using Facebook Ad Manager. $m$ Health (Advanced online publication). https://doi.org/10.21037/ mhealth-19-237a

Frank, L. B., Chatterjee, J. S., Chaudhuri, S., Lapsansky, C., Bhanot, A., \& Murphy, S. T. (2012). Conversation and compliance: Role of interpersonal 
discussion and social norms in public communication campaigns. Journal of Health Communication, 17(9), 1050-1067. https://doi.org/10.1080/ 10810730.2012 .665426

Frank, L. B., Jodrell, D., \& Smethurst, L. (2017). Social and structural factors to promote maternal health in Bangladesh. Journal of Communication in Healthcare, 10(3), 216-225. https://doi.org/10.1080/1753806 8.2017 .1313640

Green, D. P. (2021). In search of entertainment-education's effects on attitudes and behaviors. In L. B. Frank \& P. Falzone (Eds.), Entertainment-education behind the scenes: Case studies for theory and practice. Palgrave Macmillan.

Johnstone, M. (2007). I had a black dog: His name was depression. Constable \& Robinson.

Nielsen. (2015, September 28). Recommendations from friends remain most credible form of advertising among consumers; branded websites are the second-highest-rated form. Retrieved from https://www.nielsen.com/us/en/ press-releases $/ 2015 /$ recommendations-from-friends-remain-most-credibleform-of-advertising/

Penney, J. (2015). Social media and symbolic action: Exploring participating in the Facebook red equal sign profile picture campaign. Journal of ComputerMediated Communication, 20(1), 52-66. https://doi.org/10.1111/ jcc4.12092

Pew Research Center. (2019). Public trust in government: 1958-2019. Retrieved from https://www.pewresearch.org/politics/2019/04/11/public-trust-ingovernment-1958-2019/

Shi, J., Poorisat, T., \& Salmon, C. T. (2018). The use of social networking sites (SNSs) in health communication campaigns: Review and recommendations. Health Communication, 33(1), 49-56. https://doi.org/10.1080/1041023 6.2016 .1242035

Sood, S. (2002). Audience involvement and entertainment-Education. Communication Theory, 12(2), 153-172. 
Open Access This chapter is licensed under the terms of the Creative Commons Attribution-NonCommercial-NoDerivatives 4.0 International License (http:// creativecommons.org/licenses/by-nc-nd/4.0/), which permits any noncommercial use, sharing, distribution and reproduction in any medium or format, as long as you give appropriate credit to the original author(s) and the source, provide a link to the Creative Commons licence and indicate if you modified the licensed material. You do not have permission under this licence to share adapted material derived from this chapter or parts of it.

The images or other third party material in this chapter are included in the chapter's Creative Commons licence, unless indicated otherwise in a credit line to the material. If material is not included in the chapter's Creative Commons licence and your intended use is not permitted by statutory regulation or exceeds the permitted use, you will need to obtain permission directly from the copyright holder. 